\title{
Modelling the formation of shoreface-connected sand ridges on storm-dominated inner shelves
}

\author{
By D. CALVETE ${ }^{1,2}$, A. FALQUES ${ }^{1}$, H. E. DE SWART \\ AND M. WALGREE ${ }^{2}$ \\ ${ }^{1}$ Departament de Física Aplicada, Universitat Politècnica de Catalunya, \\ 08034 Barcelona, Spain \\ ${ }^{2}$ Institute for Marine and Atmospheric Research, Utrecht University, 3584 CC Utrecht, \\ The Netherlands
}

(Received 25 February 2000 and in revised form 26 October 2000)

\begin{abstract}
A morphodynamic model is developed and analysed to gain fundamental understanding of the basic physical mechanisms responsible for the characteristics of shorefaceconnected sand ridges observed in some coastal seas. These alongshore rhythmic bed forms have a horizontal lengthscale of order $5 \mathrm{~km}$ and are related to the mean current along the coast: the seaward ends of their crests are shifted upstream with respect to where they are attached to the shoreface. The model is based on the two-dimensional shallow water equations and assumes that the sediment transport only takes place during storms. The flux consists of a suspended-load part and a bed-load part and accounts for the effects of spatially non-uniform wave stirring as well as for the preferred downslope movement of sediment. The basic state of this model represents a steady longshore current, driven by wind and a pressure gradient. The dynamics of small perturbations to this state are controlled by a physical mechanism which is related to the transverse bottom slope. This causes a seaward deflection of the current over the ridges and the loss of sediment carrying capacity of the flow into deeper water. The orientation, spacing and shape of the modelled ridges agree well with field observations. Suspended-load transport and spatially non-uniform wave stirring are necessary in order to obtain correct e-folding timescales and migration speeds. The ridge growth is only due to suspended-load transport whereas the migration is controlled by bed-load transport.
\end{abstract}

\section{Introduction}

Shoreface-connected sand ridges are elongated rhythmic bed forms (typical wavelengths of $4-10 \mathrm{~km}$ ) found in the inner part of some continental shelves. Such ridges are present, for example, near the east coast of the United States of America (Duane et al. 1972; Swift et al. 1985), on the inner shelf along the Argentine coast (Parker, Lanfredi \& Swift 1982), near the German coast (Antia 1996) and along the central Dutch coast (Van de Meene, Boersma \& Terwindt 1996). These ridges are not relict features: there is geological evidence that they are active under the present hydrodynamic conditions and their growth has taken place during the Holocene, see Swift et al. (1985) and Van de Meene et al. (1996).

The ridges start at the offshore end of the shoreface and they extend seaward forming an angle of $20^{\circ}-35^{\circ}$ with respect to the coastline. In contrast with the further offshore tidal sand banks (see e.g. Hulscher, De Swart \& De Vriend 1993), their 
orientation is not cyclonically oriented with respect to the tidal current. In fact, their orientation is related to the dominant storm-driven current: the seaward end of the ridges are shifted upstream with respect to where they are attached to the shoreface. Hereafter we will refer to this as upcurrent rotated bars.

From the field studies mentioned above it appears that the length of individual crests is between 10 and $25 \mathrm{~km}$. Their height varies from 1 to $6 \mathrm{~m}$ in water depths between 4 and $20 \mathrm{~m}$. The North American ridges and some of the Argentine ridges are asymmetric, with the seaward side steeper than their landward side. The ridges slowly migrate in the direction of the dominant current with a characteristic celerity of $1-10 \mathrm{~m} \mathrm{yr}^{-1}$. According to Van de Meene et al. (1996) they are relevant to the dynamics of the coastal system.

It has already been demonstrated by Swift et al. (1985) and Trowbridge (1995) that the frequent occurrence of storm-driven currents is important for the presence of shoreface-connected ridges. Indeed, net currents can be up to $0.5 \mathrm{~m} \mathrm{~s}^{-1}$ in the areas where the ridges are observed. At this point it becomes relevant to distinguish between micro-tidal shelves, such as along the American shelf, and meso-tidal shelves (near the Dutch and German coast: tidal currents up to $1 \mathrm{~m} \mathrm{~s}^{-1}$ ). On meso-tidal shelves bottom stresses are often sufficiently strong, even during fair weather conditions, to erode and transport sediment. Usually this results in a variety of large-scale bed forms, including tidal sand banks and shoreface-connected ridges. However, on micro-tidal shelves sediment transport mainly occurs during storms and usually the only largescale bed forms observed are shoreface-connected ridges. To limit the scope of the present study we will focus, as was done in previous studies, on the dynamics of shoreface-connected ridges on micro-tidal inner shelves. Possible extension to mesotidal shelves will be discussed in $\S 6$.

Trowbridge (1995), Falqués et al. (1998a) and Falqués, Calvete \& Montoto (1998b) have demonstrated that the growth of these features can be explained as inherent free instabilities of the coupled fluid bottom system. This approach was also used to explain other bottom patterns, such as sea ripples (Blondeaux 1990), sand waves (Hulscher 1996), nearshore bars and morphology (Hino 1974; Christensen, Deigaard \& Fredsoe 1994; Falqués, Montoto \& Iranzo 1996a,b), tidal sand banks (Huthnance 1982; Hulscher et al. 1993), and free bars in rivers (Schielen, Doelman \& De Swart 1993 , and references therein).

Trowbridge (1995) studied the morphologic stability properties of a storm-driven alongshore current, with a cross-shore gradient, on a shelf bounded by a straight coast and with a transverse slope. His model consists of the two-dimensional horizontal momentum equations and mass conservation for the water motion, supplemented with a bottom evolution equation and a parametrization of the sediment transport. A notable assumption in this model is the condition of irrotational flow. Hence production of vorticity by bottom frictional torques and Coriolis terms, which has been proven to be important for large-scale sand banks dynamics (see Zimmerman 1981; Huthnance 1982), is not considered. Furthermore, Trowbridge (1995) assumes the sediment flux to be linear in the mean flow velocity and the effect of spatially non-uniform wave stirring as well as the downslope effect on the transport direction are neglected. Despite these limitations, Trowbridge's model is able to predict the growth of topographic features similar in shape to the observed ones and with the correct orientation with respect to the current. The underlying physical mechanism is the offshore deflection of the flow over the shoals and the related loss of sedimentcarrying capacity in the offshore direction, which stems from the transverse bottom slope. However, as a result of the simplifications the model does not predict a preferred 
spacing between ridge crests. Furthermore, the ratio of the timescales related to the growth and migration of the bed forms is not in accordance with field data. Also the instability mechanism appears to be sensitive to the profile of the storm-driven current.

In order to gain further knowledge about the dynamics of shoreface-connected sand ridges we investigate in this paper a generalized and physically more realistic model for both the water and sediment motion on storm-dominated micro-tidal inner shelves. A basic assumption underlying the model is that the growth of the ridges mainly takes place during storms, as is indicated by both observations (Duane et al. 1972; Swift et al. 1978; Parker et al. 1982; Van de Meene et al. 1996; Antia 1996) and model studies (Trowbridge 1995). Stormy weather, which occurs during a certain time fraction $\mu$ (typically $\mu \sim 0.01-0.05$ ), is characterized by large wave orbital velocity amplitudes compared with the mean depth-averaged current. The combined action of wave stirring and net currents causes a significant suspended-load sediment transport on the inner shelf, see e.g. Niedoroda, Swift \& Hopkins (1984), Niedoroda \& Swift (1991) and Green et al. (1995), whereas during fair weather there is hardly any sediment transport. This motivates the use of a probabilistic model, in which a fair weather state and a stormy weather state are distinguished. To study the growth of the ridges, only the equations of motion which are representative for storm conditions have to be considered.

The fluid will be described by the full two-dimensional shallow water equations which include bottom friction and Coriolis terms. The sediment flux will consist of both a suspended-load part and a bed-load part and accounts for the effects of depthdependent stirring by waves and the preferred downslope movement of the sediment. It will be shown that these extensions result in good agreement between model predictions and field observations. In particular the incorporation of suspended-load fluxes and depth-dependent stirring, which have not been considered in this context before, is crucial to obtain realistic growth rates for the ridges.

In the next section the model equations and boundary conditions are formulated. Section 3 discusses the solution procedure. The results for the growth rates, migration speeds and spatial patterns of the bed forms and the water motion are investigated in $\S 4$. The robustness of the model with respect to changing parameter values is discussed and the model results are compared with field data. In $\S 5$ the physical mechanisms within the model are discussed, followed by a discussion in $\S 6$ and some concluding remarks in the final section.

\section{Model formulation}

\subsection{Equations of motion}

As shown in figure 1, the inner shelf is schematized as a sloping seabed, bounded by a straight vertical wall which represents the seaward end of the shoreface. Further offshore, a horizontal flat bottom shows the outer shelf. An orthogonal coordinate system is taken with the $x$-, $y$ - and $z$-axes pointing in the cross-shore, longshore and vertical directions, respectively. The still water level is represented by $z=0$. The fluid motions are considered to be governed by the depth- and wave-averaged shallow water equations:

$$
\begin{gathered}
\frac{\partial \boldsymbol{v}}{\partial t}+(\boldsymbol{v} \cdot \nabla) \boldsymbol{v}+f \boldsymbol{e}_{z} \times \boldsymbol{v}=-g \nabla z_{s}+\frac{\tau}{\rho D}, \\
\frac{\partial D}{\partial t}+\nabla \cdot(D \boldsymbol{v})=0 .
\end{gathered}
$$




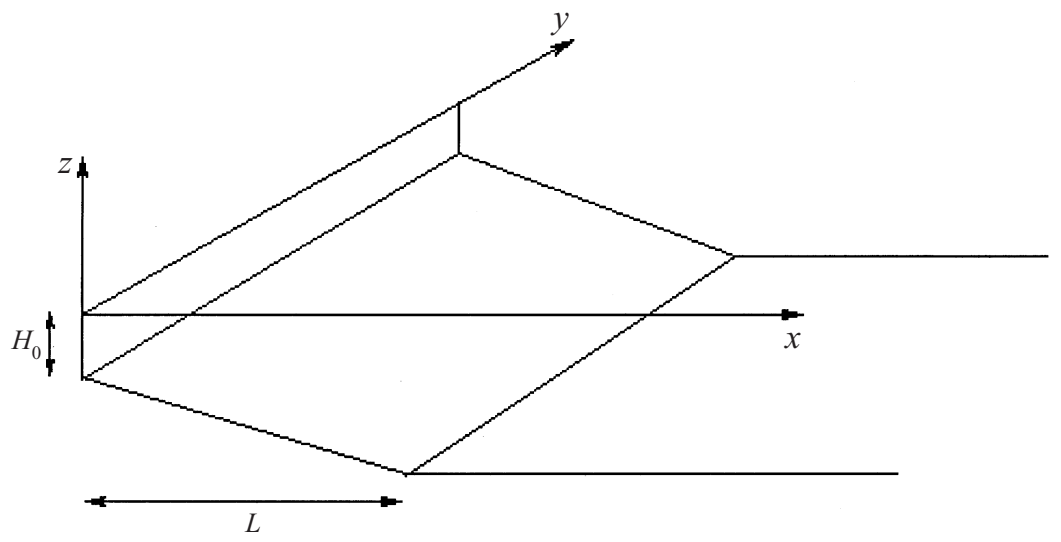

FIGURE 1. Sketch of the geometry and the coordinate system. For explanation of the symbols see the text.

Here $\boldsymbol{v}$ is the current vector, $f \sim 10^{-4} \mathrm{~s}^{-1}$ is the Coriolis parameter, $\boldsymbol{e}_{z}$ is a unity vector in the vertical direction, $\tau$ represents the free surface and bottom stress terms $\left(\tau=\tau_{s}-\tau_{b}\right)$ and $\rho$ is the water density. In the momentum equations (2.1) forcing terms caused by wave-induced radiation stresses and horizontal momentum diffusion can also be considered, but they are neglected in the present study. The free surface, the bottom and the total height of the water column are given by $z=z_{s}, z=z_{b}$ and $D$, with $z_{b}=-H(x)+h$ and $D=z_{s}+z_{b}$. Here $H(x)$ is the mean bathymetry of the inner shelf (averaged over time and the longshore direction) and $h$ the bottom elevation with respect to the mean profile. The nabla-operator is defined by $\nabla=(\partial / \partial x, \partial / \partial y)$. The bottom evolution follows from the sediment conservation equation:

$$
(1-p) \frac{\partial z_{b}}{\partial t}+\nabla \cdot \boldsymbol{q}=0,
$$

where $\boldsymbol{q}$ denotes the volumetric sediment flux, excluding the pores, per unit width and $p$ is the bed porosity $(p \sim 0.4)$.

As was already explained in the introduction, the growth of the ridges mainly occurs during storms and take place on a long timescale, $O\left(10^{3}\right)$ yr. Hence, all the governing equations and state variables are assumed to be representative for storm conditions. Furthermore we remark that the wave motion is not explicitly modelled, but only used in a parametric way to determine the bed shear stress $\tau_{b}$ and the sediment flux $\boldsymbol{q}$.

The boundary conditions are that at $x=0$ (the transition from shoreface to inner shelf) and for $x \rightarrow \infty$ the cross-shore flow component vanishes and the bottom elevation is fixed to its reference value. These conditions are motivated by the fact that the ridges are trapped at the inner shelf and that exchange processes between inner shelf and shoreface can be neglected. Notice that the condition of vanishing perturbations far offshore is consistent with the fact that we are looking for inherent instabilities of the inner shelf rather than forced behaviour driven by offshore features.

\subsection{Bed shear stress and sediment transport during storms}

In order to close the model the bed shear stress $\tau_{b}$ and the sediment flux $\boldsymbol{q}$ during stormy weather conditions (wave orbital velocities are large compared to the mean currents) have to be specified. The mean bottom stress is described by the linear 
friction law

$$
\tau_{b}=\rho r_{*} \boldsymbol{v},
$$

where the friction coefficient $r_{*}$ is proportional to the amplitude $u_{w}$ of the wave orbital velocity. Note that the bottom friction is related to the depth-averaged velocity, rather than to the bottom velocity. This approach follows from Jenter \& Madsen (1989) where theoretical values for both a linear and a quadratic drag coefficient are computed. In principle a quadratic bed shear stress could also be used in (2.4), but Falqués et al. (1998b) have shown that this has only a minor effect on the final results.

In this study it is assumed that $u_{w}$, and thereby $r_{*}$, is a function of the mean undisturbed water depth $H$ which only depends on the cross-shore coordinate $x$. A crude parametrization, which accounts for the decreasing wave activity in larger water depths, is

$$
u_{w}=u_{w 0}\left(\frac{H}{H_{0}}\right)^{-m / 2}, \quad r_{*}=r_{* 0}\left(\frac{H}{H_{0}}\right)^{-m / 2} .
$$

This result is derived from a simple wave shoaling model, in which it is assumed that the waves are linear and nearly symmetrical. Note that a depth-dependent linear friction coefficient is consistent with the field measurements on the inner shelf, as discussed by Lentz \& Winant (1986). The required input conditions are the values at $x=0$ of the water depth $H_{0}$, the wave orbital velocity amplitude $u_{w 0}$ and the friction coefficient $r_{* 0}$, as well as the coefficient $m$. Characteristic values for the Long Island inner shelf, which is considered in this paper as a default test case for our model, are $H_{0} \sim 14 \mathrm{~m}, u_{w 0} \sim 1.0 \mathrm{~m} \mathrm{~s}^{-1}, r_{* 0} \sim 1.0 \times 10^{-3} \mathrm{~m} \mathrm{~s}^{-1}$, and $m \sim 1.6$. Typically, $m=1$ corresponds to shallow water waves.

With regard to the volumetric sediment flux per unit width $\boldsymbol{q}$, field observations by Green et al. (1995) indicate that during storms a large amount of sediment is transported as suspended load (denoted by $\boldsymbol{q}_{s}$ ), but also the bed-load part (denoted by $\boldsymbol{q}_{b}$ ) contributes to the total flux. Hence, we write

$$
\boldsymbol{q}=\boldsymbol{q}_{s}+\boldsymbol{q}_{b} .
$$

For the bed-load flux the formulation of Bailard (1981) is used, in which the sediment flux is related to the work done by the flow on the grains, which is cubic in the instantaneous velocity. Moreover the formulation accounts for the tendency of the sand to move downslope. For stormy weather conditions the wave-averaged bed-load flux of Bailard (1981) becomes

$$
\boldsymbol{q}_{b}=v_{b}\left[u_{w}^{2} \boldsymbol{v}-\lambda_{b} u_{w}^{3} \nabla h\right] .
$$

Here $v_{b}$ is a coefficient (which depends on the sediment properties) and $\lambda$ is the Coulomb friction coefficient related to the angle of repose of the sediment. Typical values for medium to fine sand are $v_{b} \sim 4 \times 10^{-5} \mathrm{~s}^{2} \mathrm{~m}^{-1}$ and $\lambda_{b} \sim 0.4$, where $v_{b}$ is computed for waves which propagate in almost the same direction as the mean current. The first term on the right-hand side of equation (2.7) can be interpreted as a net flux due to the combined effect of stirring by waves and transport by the current. Here $v_{b} u_{w}^{2}$ is the wave stirring coefficient which is equivalent to the coefficient $K(x)$ mentioned by Trowbridge (1995).

According to Bailard (1981), the volumetric suspended-load sediment flux also consists of two parts:

$$
\boldsymbol{q}_{s}=\boldsymbol{q}_{s 1}+\boldsymbol{q}_{s 2} .
$$


Here $\boldsymbol{q}_{s 1}$ is proportional to a power of the instantaneous velocity and $\boldsymbol{q}_{\mathrm{s} 2}$ is proportional to the local bed slope. Although this concept is adopted in the present study, a different parametrization for $\boldsymbol{q}_{s 1}$ will be used. The reason for this is that the Bailard (1981) formulation is only applicable when the characteristic thickness of the sediment layer is of the order of the wave boundary layer (typically a few centimetres). On the contrary, during storms the sediment layer is much thicker, because the combined effects of waves and currents cause a very effective mixing of sediment over the water column, see Van Rijn (1993). To account for this the following parametrizations have been used:

$$
\boldsymbol{q}_{s 1}=\boldsymbol{v} \mathscr{C}, \quad \boldsymbol{q}_{s 2}=-\lambda_{s} u_{w}^{5} \nabla h .
$$

Here $\mathscr{C}$ is the depth-integrated relative volume concentration (i.e. the volume of sediment per surface area) and $\lambda_{s}$ is a coefficient. The latter will be chosen such that the relative magnitude of flux $\boldsymbol{q}_{s 2}$, with respect to $\boldsymbol{q}_{s 1}$, is the same as in the original formulation of Bailard (1981).

To compute the flux $\boldsymbol{q}_{s 1}$ in (2.8) we use that the concentration is described by

$$
\frac{\partial \mathscr{C}}{\partial t}+\nabla \cdot(\boldsymbol{v} \mathscr{C})=w_{s}\left(c_{a}-c_{b}\right),
$$

with $w_{s}$ the settling velocity of the sediment grains, $c_{a}$ the reference volume concentration (such that $w_{s} c_{a}$ is the sediment pick-up function) and $c_{b}$ is the actual volume concentration near the bed. Note that diffusive effects have been neglected in (2.10), because they are very small with respect to the other contributions. The corresponding boundary condition is that the concentration vanishes far from the coast.

For the reference volume concentration the parametrization according to Van Rijn (1993) has been adopted, which for stormy weather conditions is

$$
c_{a}=\left(\frac{u_{w}}{\hat{u}}\right)^{3} .
$$

Here $\hat{u}$ is a velocity which is proportional to the critical velocity for erosion of sediment. For medium to fine sand (grain size of $4 \times 10^{-4} \mathrm{~m}$ ) $w_{s} \sim 0.05 \mathrm{~m} \mathrm{~s}^{-1}$ and $\hat{u} \sim 10 \mathrm{~m} \mathrm{~s}^{-1}$, hence $c_{a} \sim 10^{-3}$. This yields dimensional reference concentrations of the order of $0.1 \mathrm{~kg} \mathrm{~m}^{-3}$, which are of the same order as measured reference concentrations near the Middelkerke Bank (North Sea, near Belgium) reported by Williams et al. (1999).

Finally the near-bed concentration in equation (2.10) is modelled as

$$
c_{b}=\frac{\mathscr{C}}{\delta D},
$$

with $\delta$ the ratio of the characteristic thickness of the suspended-load sediment layer and the actual water depth. Here $\delta D / w_{s}$ is a characteristic timescale for sediment deposition. From field data, see e.g. Williams et al. (1999), it follows that $\delta \sim 0.15$ for strong waves superimposed on a mean current. It is further assumed that this parameter is a constant. The motivation for this is that turbulence is generated both near the bottom and at the free surface (by whitecapping). Hence the turbulent mixing of sediment during storms is proportional to the actual water depth and this determines the sediment layer thickness. The result is consistent with the parametrizations of the vertical diffusion coefficient of sediment as discussed e.g. in Van Rijn (1993) and Fredsoe \& Deigaard (1993). We will return to this point in the $\S 6$.

At the shoreface boundary $(x=0)$, the cross-shore advective sediment transport flux 
component vanishes. Locally there is a small sediment flux due to diffusive processes. However in the forthcoming analysis (see $\S 3.3) h$ will be periodic in the alongshore direction, hence the alongshore average of this contribution is zero. Consequently, there is no net sediment supply from the shoreface and all sediment is sourced by local resuspension.

\subsection{Final equations of motion}

Substitution of the expressions (2.6)-(2.9) in equation (2.3) results in the final bottom evolution equation

$$
(1-p) \frac{\partial h}{\partial t}+\nabla \cdot\left[\boldsymbol{v} \mathscr{C}-\lambda_{s} u_{w}^{5} \nabla h\right]+v_{b} \nabla \cdot\left[u_{w}^{2} \boldsymbol{v}-\lambda_{b} u_{w}^{3} \nabla h\right]=0 .
$$

Here use has been made of the fact that $z_{b}=-H+h$, where the mean bathymetry $H$ is time-independent. In the final results use is made of the fact that sediment transport only takes place during storms, which occur during a certain time fraction.

Furthermore, the water motion is described by equations (2.1)-(2.2), the wave orbital velocity amplitude is given in (2.5) and the sediment concentration follows from equations (2.10)-(2.12).

\section{Basic state, scaling and stability analysis}

\subsection{Basic state}

Field observations of the bathymetry of the inner shelf indicate that the mean bottom profile (i.e. averaged in the longshore direction) is characterized by a nearly constant slope $\beta_{*}$. The slope of the outer shelf is considerably smaller. In this study we model the reference bottom profile as

$$
H(x)= \begin{cases}H_{0}+\beta_{*} x & (0 \leqslant x \leqslant L) \\ H_{s} & (x>L) .\end{cases}
$$

Here $H_{0}$ is the water depth at the transition from shoreface to inner shelf, $L$ is the width of the inner shelf and $H_{s}$ the water depth on the outer shelf. For example, representative values for the Long Island inner shelf are $H_{0} \sim 14 \mathrm{~m}, L \sim 5.5 \times 10^{3} \mathrm{~m}$, $H_{s} \sim 20 \mathrm{~m}$, so $\beta_{*} \equiv\left(H_{s}-H_{0}\right) / L \sim 1.1 \times 10^{-3}$.

Now, we will consider the possibility of a mean longshore current with a cross-shore gradient, $V(x)$, which is driven by the mean alongshore wind stress $\tau_{s y}$ and the mean longshore gradient in the free surface elevation, $s$, both assumed to be uniform. The corresponding volume concentration of sediment per surface area is $C(x)$.

The supposition of a steady reference current implies a basic state of the form

$$
\boldsymbol{v}=(0, V(x)), \quad z_{s}=s_{*} y+\xi(x), \quad \mathscr{C}=C(x), \quad z_{b}=-H(x),
$$

where $H(x)$ is given in (3.1). The momentum equations and concentration equation are

$$
f V=g \frac{\mathrm{d} \xi}{\mathrm{d} x}, \quad 0=-g S_{*}+\frac{\left(\tau_{s y}-\tau_{b y}\right)}{\rho D_{*}}, \quad C=\delta D_{*}\left(\frac{u_{w}}{\hat{u}}\right)^{3} .
$$

However, the total depth, $D_{*}=H(x)+s_{*} y+\xi(x)$, introduces a dependence on the alongshore coordinate in the second and third equations of (3.3). A consistent system is obtained by the using the fact that the deformation of the mean free surface is much smaller than the depth below still water level, i.e. $\left|s_{*} y+\xi(x)\right| \ll|H(x)|$. This allows us to approximate $D_{*}$ by $H$ in this equation so that the $y$-dependence becomes 
negligible. The consistency of this assumption can be checked as follows. From the cross-shore balance, since $V \sim 0.5 \mathrm{~m} \mathrm{~s}^{-1}, f \sim 10^{-4} \mathrm{~s}^{-1}$ and the width of the inner shelf is $\Delta x \sim 10^{4} \mathrm{~m}$, the setup/setdown caused by the Coriolis effect can be estimated to be less than $\sim 0.05 \mathrm{~m}$, that is, much smaller than $H \sim 15 \mathrm{~m}$. Furthermore, according to observations on the east North American inner shelf (Scott \& Csanady 1976; see also Chase 1979), the longshore gradient in the sea surface elevation $S_{*} \sim 2 \times 10^{-7}$, which over a distance of $\Delta y \sim 100 \mathrm{~km}$, would make $\Delta z_{s} \sim 0.2 \mathrm{~m}$.

It has been demonstrated by Scott \& Csanady (1976) and by Lentz et al. (1999) that the momentum balances in equation (3.3) using the linear friction law (2.4), together with $(2.5)$ and with $D_{*}$ replaced by $H$, yield a good description of mean currents in the inner shelf region of micro-tidal coastal areas. In that case the basic state alongshore velocity profile and corresponding concentration are

$$
V=\frac{\tau_{s y} / \rho-g s_{*} H}{r_{*}}, \quad C=\delta H\left(\frac{u_{w}}{\hat{u}}\right)^{3},
$$

where $r_{*}$ and $u_{w}$ are defined in equation (2.5). Substitution of (3.2) in (2.2) and in (2.13) shows that the mass conservation equation is verified identically. Furthermore, $(\partial h / \partial t)=0$, because there are no spatial divergences in the (alongshore directed) sediment transport. The formulation of the model excludes the diffusive fluxes of the basic state by formulating the bedslope effects only for the bottom perturbations. It is implicitly assumed that the basic inner shelf equilibrium profile is due to the balance between downslope gravitational transport and onshore wave transport (wave asymmetry, Stokes drift, etc.). Consequently, (3.2) defines a morphodynamic equilibrium situation.

The current profile in equation (3.4) is the result of a balance between forces related to the longshore pressure gradient, wind stress and bottom friction. The sign of the velocity is determined by the direction of the wind stress and that of the pressure gradient force. Based on the field data discussed above we choose $\tau_{s y} \simeq-0.4 \mathrm{~N} \mathrm{~m}^{-2}$ and $s_{*} \simeq 2 \times 10^{-7}$. This yields an estimate of the longshore velocity scale: $U \equiv|V(x=0)| \simeq 0.43 \mathrm{~m} \mathrm{~s}^{-1}$. This implies that both the longshore wind stress and pressure gradient force a flow in the same, negative, $y$-direction. Note that with this choice of wind stress we have $\tau_{s y} / \rho \sim 4 \times 10^{-4} \mathrm{~m}^{2} \mathrm{~s}^{-2}$ while $g_{s_{*}} H \sim 3 \times 10^{-5} \mathrm{~m}^{2} \mathrm{~s}^{-2}$, so that both terms play a role in equation (3.4). This is confirmed by the field observations on the inner shelf presented in Lentz et al. (1999).

Instead of using analytical profiles, observed current structures over the inner shelf can be used, but data are scarce. Results for the east North American shelf (near Long Island) are presented in Niedora \& Swift $(1981,1991)$. During storms depth-averaged currents tend to increase with increasing offshore distance on the inner shelf and weakly decay on the outer shelf. Comparison with the analytical profiles suggest that both the spatially non-uniform wave stirring and the longshore pressure gradient are important for the maintenance of the flow.

Finally we consider the characteristic magnitudes of the bed-load and suspendedload sediment fluxes and of the depth-integrated concentration. Taking $U$ as a typical scale for the mean current, it follows from equation (2.7) that a scale for the volumetric bed-load flux per unit width is $Q_{b}=v_{b} u_{w 0}^{2} U \sim 1.8 \times 10^{-5} \mathrm{~m}^{2} \mathrm{~s}^{-1}$. Similarly, equation (2.9) determines the scale of the suspended-load volumetric flux per unit width, which becomes $Q_{s}=U C_{0}$, where $C_{0}$ is the scale for the depth-integrated concentration. The latter follows from equation (3.4) and becomes $C_{0}=\delta H_{0}\left(u_{w 0} / \hat{u}\right)^{3} \sim 1.8 \times 10^{-3} \mathrm{~m}$. This yields $Q_{s} \sim 7.9 \times 10^{-4} \mathrm{~m}^{2} \mathrm{~s}^{-1}$ which is consistent with that reported by Green et al. (1995). 


\subsection{Non-dimensional equations of motion}

For further analysis it is convenient to make the equations of motion dimensionless. Therefore we introduce characteristic magnitudes $L, U, H_{0}$ and $u_{w 0}$ for the horizontal length, the longshore current, the depth and the wave-orbital velocity amplitude at the transition $x=0$ from inner shelf to shoreface. Furthermore, the characteristic scales $Q_{b}, Q_{s}$ and $C_{0}$ for the bed-load flux, suspended-load flux and the depth-integrated concentration are used. These scales have been discussed in the previous subsection. Then three timescales appear in a natural way which are defined as

$$
T_{h}=\frac{L}{U}, \quad T_{m s}=\frac{(1-p) H_{0} L}{Q_{s}}, \quad T_{m b}=\frac{(1-p) H_{0} L}{Q_{b}} .
$$

The hydrodynamic timescale $T_{h}$ follows from scaling the three equations (2.1)-(2.2) and the two morphodynamic timescales $T_{m b}$ and $T_{m s}$ result from scaling equation (2.13). Characteristic values are $T_{h} \sim 1.2 \times 10^{4} \mathrm{~s}, T_{m s} \sim 5.9 \times 10^{7} \mathrm{~s}$ and $T_{m b} \sim 2.6 \times 10^{9} \mathrm{~s}$.

The variables are made dimensionless as follows:

$$
\begin{gathered}
t=T_{m s} \tilde{t}, \quad(x, y)=L(\tilde{x}, \tilde{y}), \quad z_{s}=\frac{U^{2}}{g} \tilde{z}_{s}, \quad z_{b}=H_{0} \tilde{z}_{b}, \\
\boldsymbol{v}=U \tilde{\boldsymbol{v}}, \quad u_{w}=u_{w 0} \tilde{u}_{w}, \quad \frac{\tau_{s}}{\rho}=\frac{H_{0}}{L} U^{2} \tilde{\tau}_{s}, \quad \mathscr{C}=C_{0} \tilde{\mathscr{C}} .
\end{gathered}
$$

The reason to scale time with $T_{m s}$ is that we wish to look for morphodynamic instabilities, which are mainly controlled by suspended-load transport. The scale for the free surface is motivated by the fact that the pressure gradient force and advective terms should be of the same order of magnitude.

The non-dimensional momentum (2.1) and mass conservation equation (2.2) are (hereafter tildes are dropped):

$$
\begin{gathered}
\epsilon \frac{\partial \boldsymbol{v}}{\partial t}+(\boldsymbol{v} \cdot \nabla) \boldsymbol{v}+\hat{f} \boldsymbol{e}_{z} \times \boldsymbol{v}=-\nabla z_{s}+\frac{\tau_{s}-\tau_{b}}{D}, \\
\epsilon \frac{\partial D}{\partial t}+\nabla \cdot(D \boldsymbol{v})=0
\end{gathered}
$$

whilst the non-dimensional concentration equation (2.10) and bottom evolution equation (2.13) are

Here

$$
\begin{gathered}
\gamma\left[\epsilon \frac{\partial \mathscr{C}}{\partial t}+\nabla \cdot(\boldsymbol{v} \mathscr{C})\right]=u_{w}^{3}-\frac{\mathscr{C}}{D}, \\
\frac{\partial h}{\partial t}+\nabla \cdot \boldsymbol{q}_{s}+\delta_{b} \nabla \cdot \boldsymbol{q}_{b}=0 .
\end{gathered}
$$

$$
\begin{gathered}
D=F^{2} z_{s}+H-h, \quad \tau_{b}=r u_{w} \boldsymbol{v}, \\
\boldsymbol{q}_{s}=\boldsymbol{v} \mathscr{C}-\hat{\lambda}_{s} u_{w}^{5} \nabla h, \quad \boldsymbol{q}_{b}=u_{w}^{2} \boldsymbol{v}-\hat{\lambda}_{b} u_{w}^{3} \nabla h,
\end{gathered}
$$

and the model parameters are

$$
\begin{gathered}
\epsilon=\frac{T_{h}}{T_{m s}}, \quad F^{2}=\frac{U^{2}}{g H_{0}}, \quad \hat{f}=\frac{f L}{U}, \quad r=\frac{r_{* 0} L}{U H_{0}}, \\
\gamma=\frac{\delta H_{0} U}{L w_{s}}, \quad \delta_{b}=\frac{Q_{b}}{Q_{s}}, \quad \hat{\lambda}_{s}=\frac{H_{0}}{L} \frac{u_{w 0}^{5}}{Q_{s}} \lambda_{s}, \quad \hat{\lambda}_{b}=\frac{H_{0}}{L} \frac{u_{w 0}}{U} \lambda_{b} .
\end{gathered}
$$


Using the characteristic numbers discussed in the previous subsection it follows that $\epsilon=O\left(10^{-4}\right), F^{2}=O\left(10^{-3}\right), \hat{f}=O(1), r=O(1), \gamma=O\left(10^{-3}\right), \delta_{b}=O\left(10^{-2}\right)$, $\hat{\lambda}_{s}=O\left(10^{-4}\right)$ and $\hat{\lambda}_{b}=O\left(10^{-3}\right)$.

The small values of the parameters $\epsilon$ and $\delta_{b}$ indicate that the hydrodynamic timescale is much smaller than the morphodynamic ones. This allows the adoption of the quasi-steady hypothesis, that is, the fluid instantaneously adjusts to the bathymetric changes. This permits the time derivatives to be dropped $(\epsilon \approx 0)$ in the hydrodynamic and concentration equations (3.6)-(3.8). The small value of the Froude number $F$ allows terms proportional to $F^{2}$ to be neglected in the forthcoming analysis. This rigid-lid approximation is consistent with the choice of our basic state, which only exists for low Froude numbers. Finally we remark that parameter $\gamma$, which measures the ratio of the deposition timescale and the advective timescale, is very small.

The dimensionless reference bathymetry and current profile become

$$
H(x)=\left\{\begin{array}{ll}
1+\beta x & \text { if } 0 \leqslant x \leqslant 1 \\
1+\beta & \text { if } x>1
\end{array}, \quad V(x)= \begin{cases} \pm(1+a \beta x) H^{m / 2} & \text { if } 0 \leqslant x \leqslant 1 \\
\pm(1+a \beta) H^{m / 2} & \text { if } x>1,\end{cases}\right.
$$

and the dimensionless free surface elevation of the basic state is

$$
z_{s} \equiv \zeta=s y+\xi, \quad C=H^{1-3 m / 2},
$$

where

$$
\beta=\frac{L}{H_{0}} \beta_{*}, \quad a=\frac{g\left|s_{*}\right| H_{0}}{r_{* 0} U}, \quad s=\frac{g s_{*} L}{U^{2}},
$$

with characteristic values $\beta=O(1), a=O\left(10^{-1}\right)$ and $s=O\left(10^{-1}\right)$. Note that $|s|=a r$. The sign of the flow is determined by the direction of the applied wind and longshore pressure gradient forces. When the pressure force and wind stress drive a current in the same direction, as is usually the case, it follows from the definition of velocity scale $U$ that $a$ can vary between 0 (no pressure gradient) and 1 (wind stress negligible).

\subsection{Stability analysis}

The formation of rhythmic bed forms can now be investigated by studying the dynamics of small perturbations evolving on the basic state defined in equation (3.2). Hence we substitute

$$
\begin{gathered}
\boldsymbol{v}=(0, V)+(u(x, y, t), v(x, y, t)), \quad z_{s}=\zeta+\eta(x, y, t), \\
\mathscr{C}=C+c, \quad z_{b}=-H+h(x, y, t),
\end{gathered}
$$

in equations (3.6)-(3.9), where all basic state variables are now to be considered as dimensionless. After linearization and using the properties of the basic state, it appears that the equations for the perturbations allow alongshore travelling and growing wave solutions with an as yet unknown cross-shore structure. Thus we consider perturbations of the form

$$
(u, v, \eta, c, h)=\operatorname{Re}\left\{(\bar{u}(x), \bar{v}(x), \bar{\eta}(x), \bar{c}(x), \bar{h}(x)) \mathrm{e}^{\mathrm{i} k y+\omega t}\right\} .
$$

Here $k$ is the wavenumber and $\omega$ a complex frequency. The real part, $\operatorname{Re}(\omega)$, denotes the growth rate of the perturbation (for continuous storms) and $-\operatorname{Im}(\omega)$ the frequency. Instability occurs if $\operatorname{Re}(\omega)$ is positive: then the mode grows exponentially in time. The part which describes the bottom is called a topographic wave. As a result the 
linearized equations for the perturbations, dropping overbars for convenience, reduce to

$$
\left(\begin{array}{cccc}
\mathrm{i} k V+\frac{r}{H^{1+m / 2}} & -\hat{f} & \frac{\mathrm{d}}{\mathrm{d} x} & 0 \\
\frac{\mathrm{d} V}{\mathrm{~d} x}+\hat{f} & \mathrm{i} k V+\frac{r}{H^{1+m / 2}} & \mathrm{i} k & 0 \\
\frac{\mathrm{d} H}{\mathrm{~d} x}+H \frac{\mathrm{d}}{\mathrm{d} x} & \mathrm{i} k H & 0 & 0 \\
\gamma\left(\frac{\mathrm{d} C}{\mathrm{~d} x}+C \frac{\mathrm{d}}{\mathrm{d} x}\right) & \gamma \mathrm{i} k C & 0 & \gamma \mathrm{i} k V+\frac{1}{H}
\end{array}\right)\left(\begin{array}{c}
u \\
v \\
\eta \\
c
\end{array}\right)=\left(\begin{array}{c}
0 \\
s / H \\
\mathrm{i} k V \\
-C / H^{2}
\end{array}\right) h
$$

and equation (3.9) becomes:

$$
\begin{aligned}
\omega h= & -\frac{\mathrm{d}}{\mathrm{d} x}\left(u C-\hat{\lambda}_{s} H^{-5 m / 2} \frac{\mathrm{d} h}{\mathrm{~d} x}\right)-\mathrm{i} k(v C+V c)-\hat{\lambda}_{s} H^{-5 m / 2} k^{2} h \\
& -\delta_{b} \frac{\mathrm{d}}{\mathrm{d} x}\left(H^{-m} u-\hat{\lambda}_{b} H^{-3 m / 2} \frac{\mathrm{d} h}{\mathrm{~d} x}\right)-\delta_{b}\left(\mathrm{i} k H^{-m} v+\hat{\lambda}_{b} H^{-3 m / 2} k^{2} h\right) .
\end{aligned}
$$

The first step is to solve equations (3.13) for $u, v, \eta$ and $c$ for a given bottom perturbation $h$. This problem will hereafter be called the flow over topography problem (FOT). Physically, this means finding the response of the flow to a given perturbation on the sea bed.

The second step is to substitute these results into the bottom evolution equation (3.14). Together with the boundary conditions, which have been discussed in the previous section, this defines an eigenvalue problem of the form

$$
\omega h=\mathbf{B} h,
$$

where $\omega$ is the eigenvalue and $h(x)$ the eigenfunction and where $\mathbf{B}$ is a linear operator which can be obtained by straightforward computations. The solutions are obtained numerically by the application of spectral methods, for details see Falqués et al. (1996a) and references therein. The numerical model which solves this problem is called MORFO25.

\section{Model results}

\subsection{Parameter setting}

In this section the results obtained with the numerical model will be presented. In $\S 4.2$ the micro-tidal inner shelf of Long Island, located at a latitude of $40^{\circ} \mathrm{N}$, will be considered as a default case. It has been selected because many data on its geometrical and physical characteristics are available, which have been discussed in $\S \S 2.2$ and 3.1. The basic-state longshore current is directed to the south, hence $V(x)$ in (3.10) is negative. This results in the following relevant default parameter values:

$$
\left.\begin{array}{rl}
\beta=0.43, \quad \hat{f}=1.19, \quad r=0.91, \quad s=6.8 \times 10^{-2}, \quad \gamma=3.43 \times 10^{-3}, \\
m=1.6, \quad \delta=0.15, \quad \delta_{b}=2.20 \times 10^{-2}, \quad \hat{\lambda}_{s}=3.50 \times 10^{-4}, \quad \hat{\lambda}_{b}=2.40 \times 10^{-3} .
\end{array}\right\}
$$



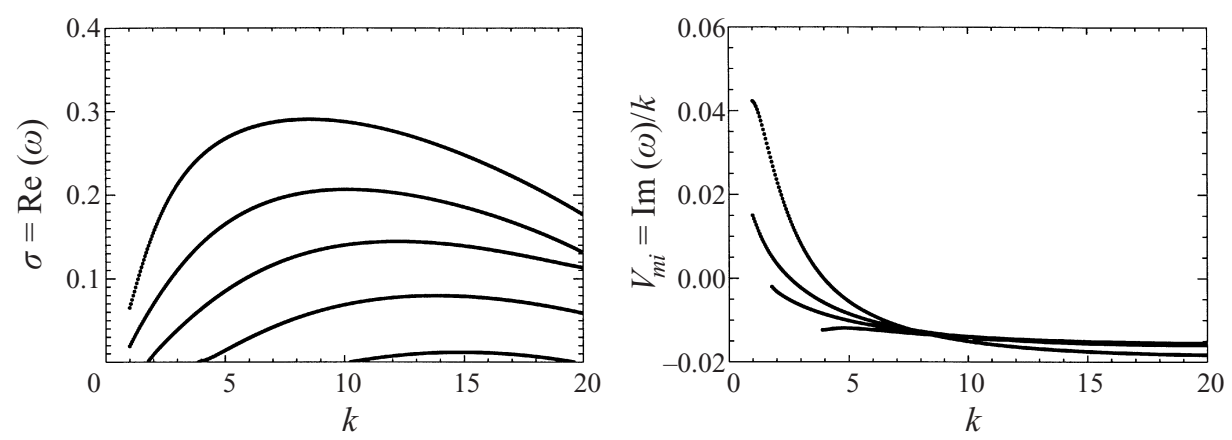

FIGURE 2. Non-dimensional growth rate and phase speed as a function of the wavenumber for the first five modes. Parameter values are given in (4.1) and representative for the Long Island inner shelf; furthermore $V<0$.

In $\S 4.3$ we will focus on the dynamics of bed forms for other micro-tidal inner shelves. Those in the northern hemisphere are characterized by a current which has the coast to the right $(\hat{f}>0, V<0)$. On the Argentine shelf the current is directed to the north $(V>0$ in the present model), so $\hat{f}<0$. However, the latter situation is equivalent to the former one because the system has a mirror symmetry with respect to the $y=0$ plane. Therefore, there are only two independent situations, $\hat{f} V<0$ and $\hat{f} V>0$.

\subsection{Default case and sensitivity experiments}

Here solutions of the morphodynamic eigenvalue problem (3.13)-(3.14) are presented for the Long Island inner shelf. The reference bathymetry and current are given in (3.10) and the parameter values are specified in (4.1). Results will be compared with observations; the physics underlying the results will be discussed in the next section.

In figure 2 curves are shown of the dimensionless growth rate $\sigma=\operatorname{Re}(\omega)$ and migration speed $V_{m i}=-\operatorname{Im}(\omega) / k$ of the first five modes as a function of the nondimensional wavenumber $k$. As can be seen all growth rate curves attain a maximum value for a specific $k$. This differs from the results of Trowbridge (1995), where the growth rates monotonically increase with increasing $k$ up to a saturation value. This difference is due to the fact that the present model accounts for the preferred downslope movement of the sediment, which is very effective for short wavelengths. The maximum growth rate is $\sigma_{\max } \sim 0.3$ and is found for $k \sim 8.5$. The dimensional longshore spacing of this so-called most preferred mode is $4.1 \mathrm{~km}$. This agrees with the observed spacing of shoreface-connected sand ridges on the Long Island inner shelf (Swift et al. 1978).

The dimensional e-folding time of this mode can be estimated as follows. For continuous storms it would be $T_{m s} / \sigma_{\max } \sim 6.3 \mathrm{yr}$, where $T_{m s}$ has been computed from (3.5). In reality storms only occur during a certain time fraction $\mu$ (typically $\mu \sim 0.05$ ), hence the e-folding timescale is

$$
\tau_{*}=\frac{1}{\sigma_{\max }} \frac{T_{m s}}{\mu} \sim 125 \mathrm{yr} .
$$

Although there are no field data to compare with, this seems quite a reasonable value considering the geological timescale of the inner shelf.

The migration speed of the modes varies between small positive values for long topographic waves (upstream propagation, since $V<0$ ) and small negative values 

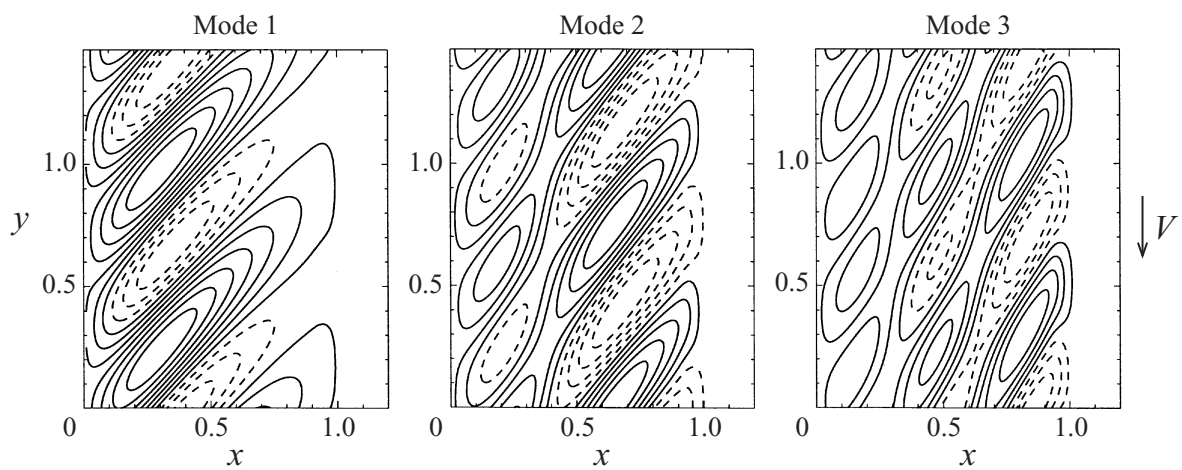

FiguRE 3. Contour plots of the three bottom modes with the largest growth rate. Shoals and pools are indicated by continuous and dashed lines, respectively. In each plot the $y$-axis represents the shoreface and the $x>0$ axis the inner shelf. The direction of the basic current is shown by an arrow. Note the upcurrent rotation of the ridges.

for shorter wavelengths. In particular, the most preferred mode has a dimensional celerity of

$$
V_{m i, *}=V_{m i} \mu \frac{L}{T_{m s}} \sim-2.1 \mathrm{~m} \mathrm{yr}^{-1},
$$

which is in the downstream direction. Both the magnitude and direction of this migration speed are in good agreement with the field data on the Long Island inner shelf. Note that the model predicts that modes having wavelengths much longer than the preferred mode move upstream. This is another difference with the results of Trowbridge (1995) and it is caused by the fact that in our model both suspended-load and bed-load transport are incorporated; see the next section for further details.

The shape of the modelled ridges is shown in figure 3 for the first three modes and for the wavenumber which corresponds to the maximum growth rate. Clearly, the orientation of the dominant bed forms is such that they are upcurrent rotated: the seaward ends of the crests are shifted upstream with respect to their shoreface attachments. This agrees well with the observed orientation of the shoreface-connected ridges, not only on the Long Island inner shelf but on any inner shelf.

Figure 4 shows a greyscale plot of the first mode in figure 3 together with the corresponding perturbation on the current. The offshore deflection of the current over the crests and the onshore deflection over the troughs can be seen, as well as the acceleration of the flow over the crests and the deceleration over the troughs. This behaviour has also been observed in the field (Swift et al. 1978).

In figure 5 the most preferred bed form is shown together with a contour plot of the perturbation in the concentration and with a vector image of the perturbation in the sediment flux. From this figure it is seen that the depth-integrated concentration is smaller over the crests than over the troughs. Furthermore, the sediment flux has an offshore component above the ridges and an onshore deflection in the trough areas. The principal direction of the perturbation in the flux coincides to a good approximation with that of the orientation of the ridges. This implies that the magnitude of the total sediment flux is larger in the trough than in the ridge areas.

In figure 6 is shown the relative contributions of both suspended-load and bedload fluxes to the total growth rate and migration speed for the first modes of figure 2. It appears that the growth of the ridges is induced merely by divergences in the suspended-load transport. The bed-load contribution is positive for $k<8$ and 


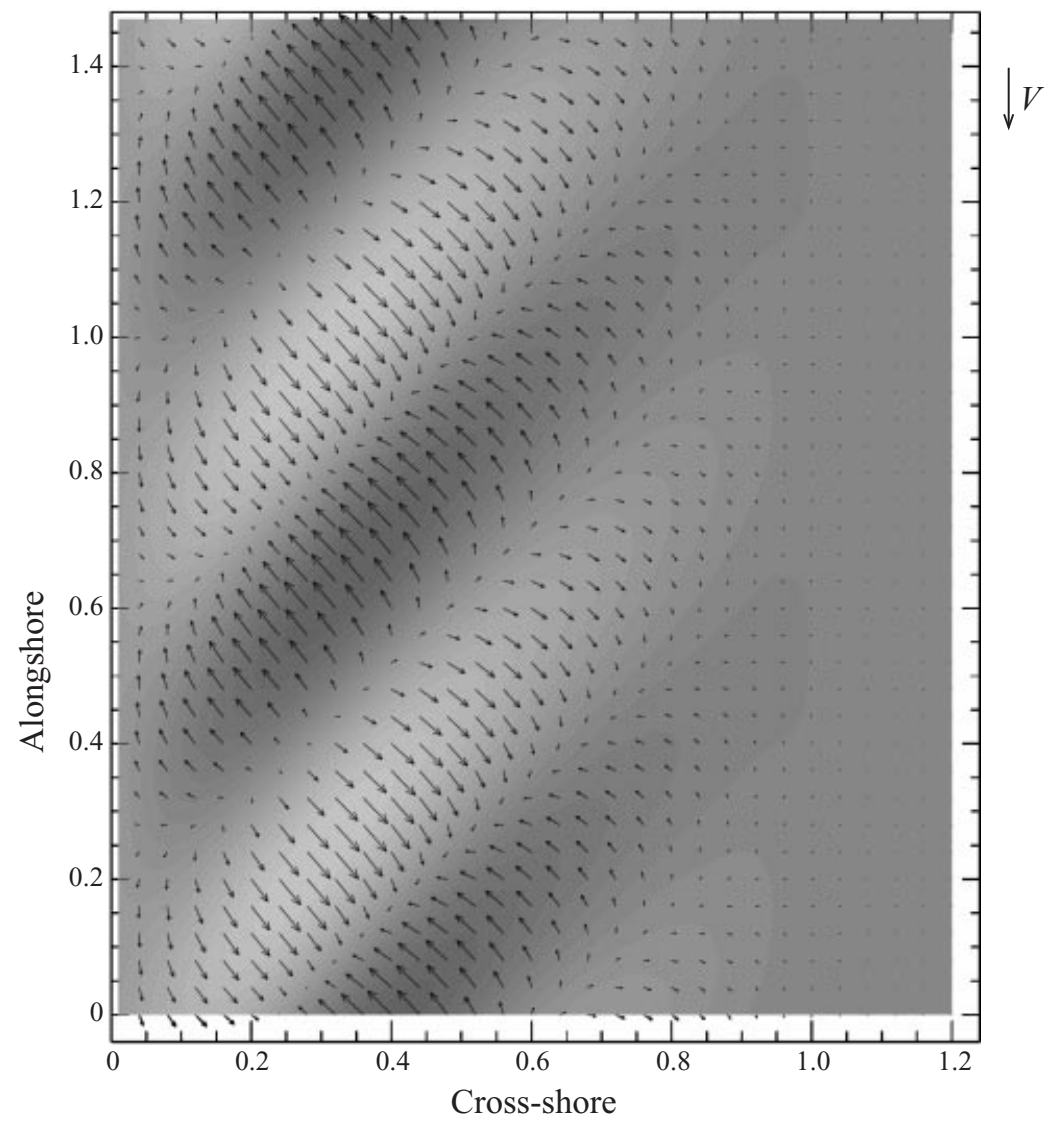

FIGURE 4. Greyscale plot of the first bottom mode in figure 3 with the associated perturbation of the current indicated by arrows. Shoals and pools are indicated by light and dark shades, respectively. Note the offshore current deflection over the crests.

negative for larger wavenumbers. However, bed-load transport cannot be neglected because it controls to a large extent the downstream migration of the ridges. Note that the sole contribution of suspended-load transport would result in an upstream migration speed. The effect of bed-load is that modes with $k>4$, including the most preferred mode, migrate downstream.

We now investigate the dependence of the model results on the parameters. This is important in order to gain knowledge about the necessary field conditions for the growth of the shoreface-connected sand ridges. For all experiments described hereafter the default values of (4.1) have been used, unless stated otherwise. First, parameter $a$ in the basic-state current profile has been changed, keeping the ratio $s / a$ fixed. Physically this means that the relative contribution of the alongshore pressure gradient to $V(x)$ is changed ( $a=1$ : pure pressure-driven flow, $a=0$ : pure winddriven flow) while keeping the bottom friction and velocity scale $U$ constant. This was done because in previous studies (Trowbridge 1995; Falqués et al. 1998a,b) it was found that the instability mechanism was strongly affected by the current profile. On the other hand, as figure 7 indicates, growth rates and migration speeds in the present model show only a weak dependence on $a$. This is due to the fact that now suspended-load transport is taken into account. We remark that the dependence of 


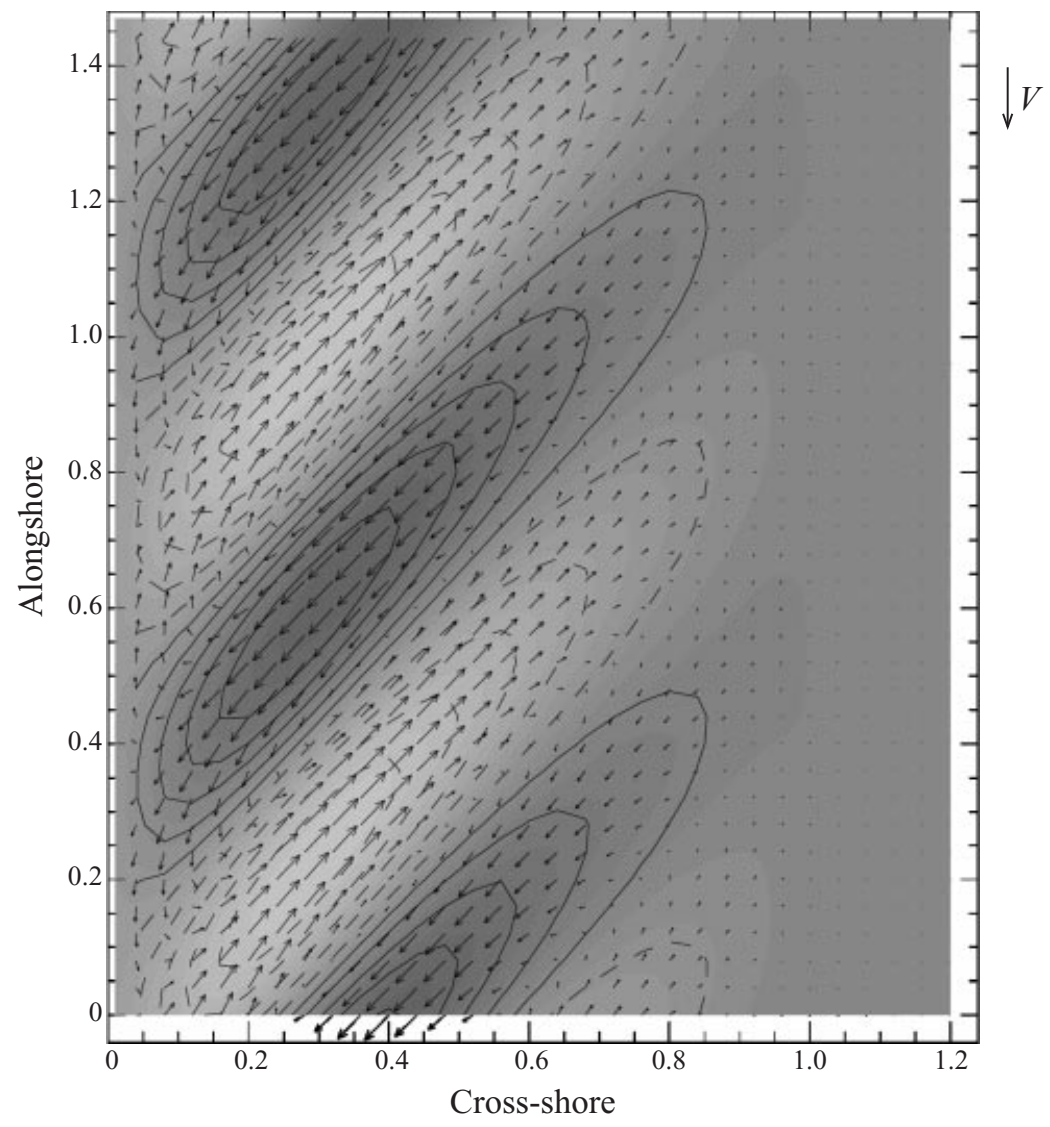

FIGURE 5. Greyscale plot of the first bottom mode in figure 3 with the associated perturbation of the sediment flux indicated by arrows. Shoals and pools are indicated by light and dark shades, respectively. The contour lines refer to the perturbation in the concentration (solid lines: positive values, dashed lines: negative values).
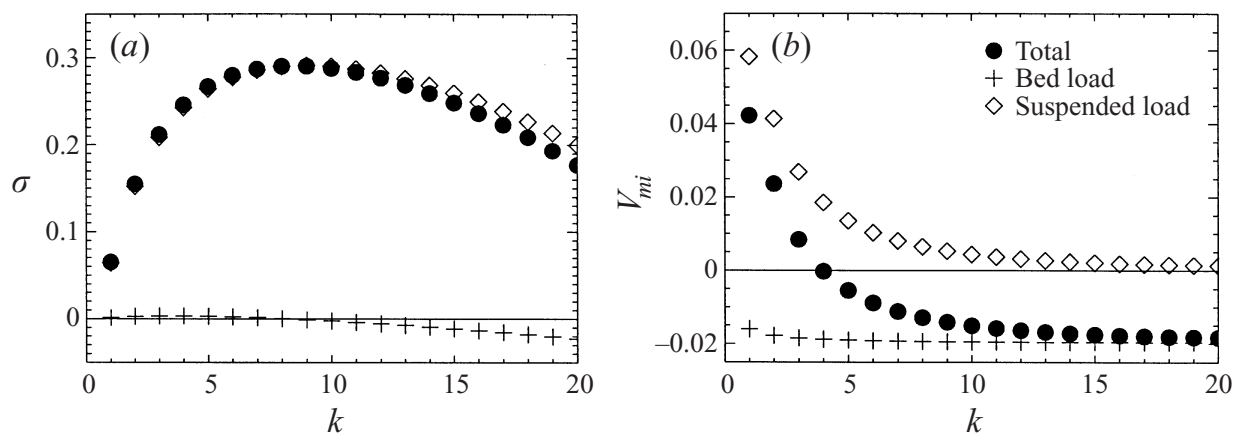

FIGURE 6. Relative contribution of suspended-load and bed-load fluxes to $(a)$ the growth rate and (b) migration speed of the first mode of figure 2.

the model results on $a$ drastically increases if the wave stirring exponent $m$ is close to zero (i.e. spatially uniform wave stirring). It is important to realize that this is not physically realistic, as typically $m>1$.

This observation suggested carrying out sensitivity experiments by varying the 

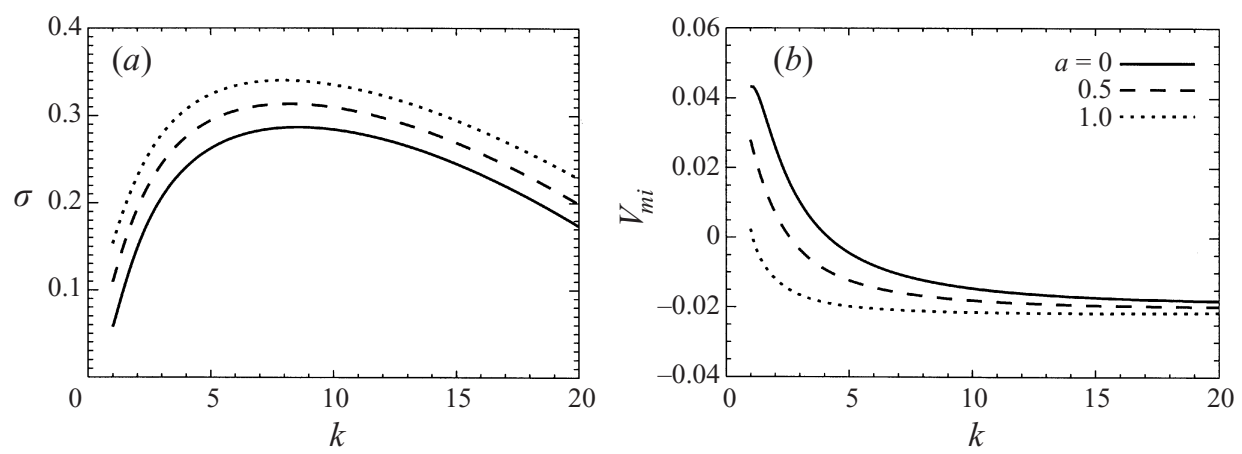

FIGURE 7. (a) Growth rate and (b) migration speed as a function of the wavenumber for $a=0,0.5$ and $a=1$; other parameters have their default values.
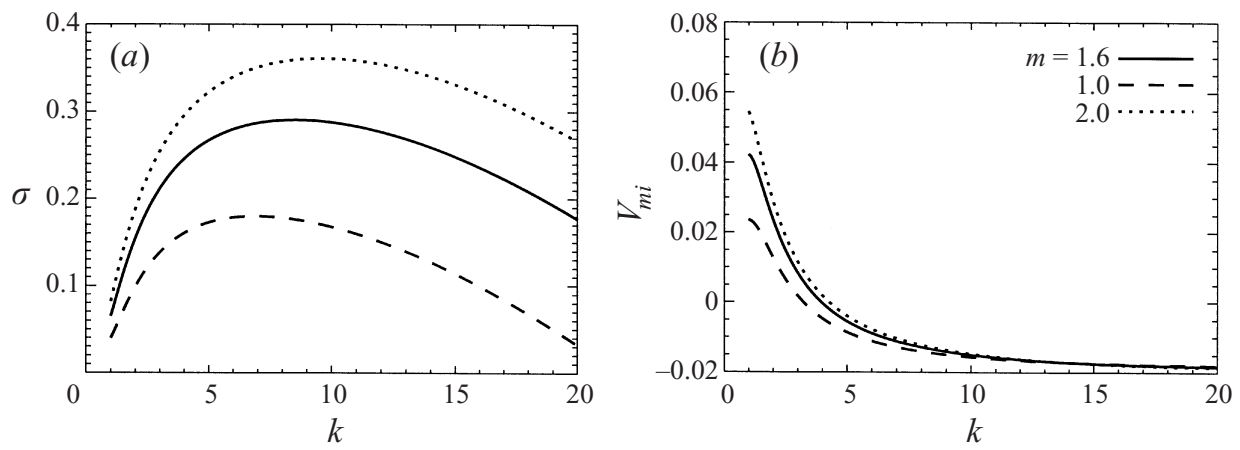

FIGURE 8. (a) Growth rate and $(b)$ migration speed as a function of the wavenumber for $m=1.0,1.6$ and $a=2$; other parameters have their default values.

exponent $m$ in the wave stirring coefficient. As can be seen from the results in figure 8, it appears that growth rates decrease with decreasing $m$ whereas the migration speeds are hardly affected. For $m=0$ (spatially uniform wave stirring) positive growth rates are only found for pressure-driven currents $(a=1)$, but they are very small: typical e-folding timescales become of the order of $10^{4} \mathrm{yr}$. The corresponding spacing is $13.3 \mathrm{~km}$ and the migration speed $-3.3 \mathrm{~m} \mathrm{~s}^{-1}$. Hence the incorporation of depthdependent wave stirring is essential to obtain growth of shoreface-connected ridges with realistic e-folding timescales and migration speeds. Also the intensity of the wave stirring itself is very important: if the near-bottom wave velocity amplitude at the shoreface is weaker than about $0.5 \mathrm{~m} \mathrm{~s}^{-1}$ then extremely long e-folding timescales are obtained.

Another parameter that has been varied is $\delta$, the ratio of the characteristic suspended-load layer thickness and the water depth. Experiments have been carried out for $\delta$ in the range between $0.1 \delta_{0}$ and $2 \delta_{0}$, where $\delta_{0}=0.15$ is the default value. Since the morphological timescale $T_{m s}$ depends on $\delta$ as well, results are shown in a relative sense, i.e. scaled with respect to their default values. Figure 9 shows the relative preferred wavelength, migration speed and e-folding timescale as a function of the ratio $\delta / \delta_{0}$. It can be seen that for $\left(\delta / \delta_{0}\right) \geqslant 0.45$ (i.e. for $\delta \geqslant 0.07$ ) results are rather insensitive to the value of $\delta$. For smaller $\delta$-values a strong increase in both the preferred spacing and the e-folding timescale is observed.

The transverse bed slope, $\beta$, and the bed slope coefficients, $\hat{\lambda}_{s}$ and $\hat{\lambda}_{b}$, have a 

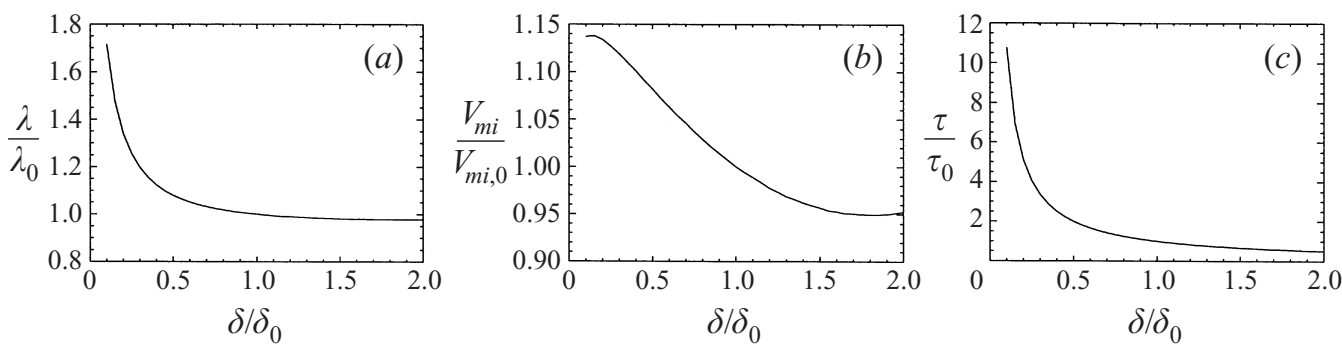

FIGURE 9. Relative $(a)$ wavelength $\lambda / \lambda_{0},(b)$ migration speed $V_{m i} / V_{m i, 0}$ and $(c)$ e-folding timescale $\tau / \tau_{0}$ as a function of the ratio $\delta / \delta_{0}$. Here subscripts 0 refer to the default values of the parameters and $\delta$ is the ratio of the suspended-load layer thickness and the water depth.
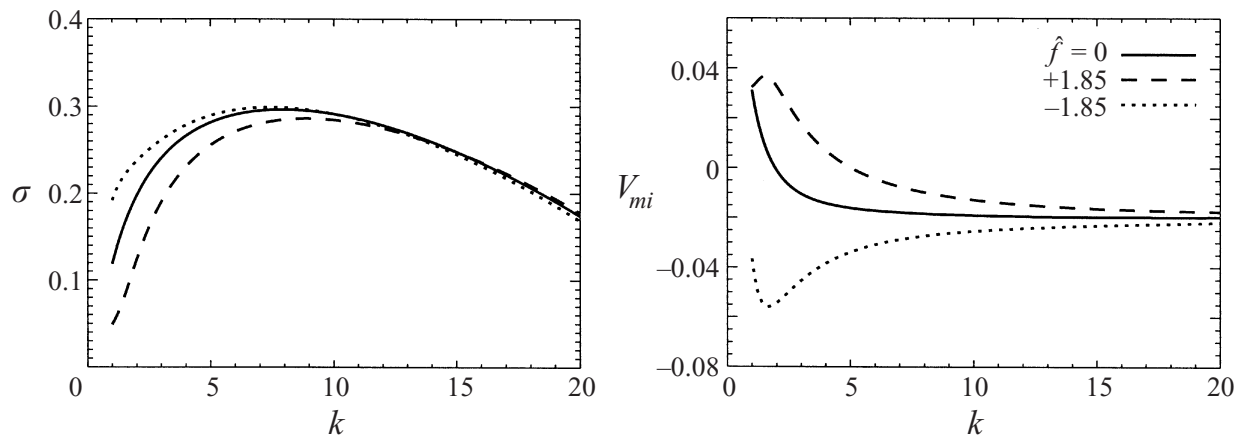

FIGURE 10. (a) Growth rate and $(b)$ migration speed of the first mode as a function of the wavenumber for different values of the Coriolis parameter $\hat{f}$. All other parameters have their default values.

significant effect on growth rates. The results of the sensitivity experiments (figure not shown) can be summarized as follows. The maximum growth rates increase monotonically with increasing $\beta$, but the characteristics of the preferred modes do not change. In contrast, increasing the value of the bed slope coefficient leads to smaller growth rates and the wavenumber of the most preferred mode shifts to smaller values. The instability mechanism is hardly affected if parameter $\gamma$, which is a measure of settling lag effects, is varied within realistic bounds. This indicates that in equation (3.13) settling effects can be neglected to a good approximation.

We also investigated the sensitivity of the model results to variations in the grain size. Considering finer sediment results in a reduction of the settling velocity and in an increase of the reference concentration ( $\hat{u}$ in equation (2.11) will decrease), hence the suspended-load timescale will become smaller. This results in larger values of the dimensionless parameters $\gamma$ and $\lambda_{s}$ and a smaller value of $\delta_{b}$. The observed trend is that with decreasing grain size the preferred mode is characterized by a smaller e-folding timescale, larger spacing and a slower migration speed. For example for a grain size of $2.5 \times 10^{-4} \mathrm{~m}$ the e-folding timescale is $60 \mathrm{yr}$, the spacing is $5 \mathrm{~km}$ and the migration $-0.9 \mathrm{~m} \mathrm{yr}^{-1}$; whereas for coarser sediment $\left(5 \times 10^{-4} \mathrm{~m}\right)$ these values are $250 \mathrm{yr}, 4.0 \mathrm{~km}$ and $-2.4 \mathrm{~m} \mathrm{yr}^{-1}$, respectively.

The effect of Earth's rotation on the instability mechanism has been investigated by carrying out experiments with all parameters having their default values and different values of the Coriolis parameter: $\hat{f}=0,1.85,-1.85$, representative of an inner shelf which is located at the equator, the North Pole and the South Pole, respectively. 


\begin{tabular}{lcccc}
\hline & Long Island & Maryland & Florida & Argentina \\
& & & & \\
Location and geometry & $40^{\circ} \mathrm{N}$ & $38^{\circ} \mathrm{N}$ & $27^{\circ} \mathrm{N}$ & $37^{\circ} \mathrm{S}$ \\
latitude & 14 & 10 & 10 & 10 \\
$H_{0}(\mathrm{~m})$ & 20 & 17 & 15 & 15 \\
$H_{s}(\mathrm{~m})$ & 5.5 & 15 & 12 & 14 \\
$L(\mathrm{~km})$ & & & & \\
Water motion and sediment fluxes & 1.0 & 1.3 & 1.0 & 1.0 \\
$u_{w 0}\left(\mathrm{~m} \mathrm{~s}^{-1}\right)$ & 1.0 & 1.3 & 1.0 & 1.0 \\
$r_{* 0}\left(\times 10^{-3} \mathrm{~m} \mathrm{~s}^{-1}\right)$ & 0.43 & 0.31 & 0.40 & 0.40 \\
$U\left(\mathrm{~m} \mathrm{~s}^{-1}\right)$ & 1.6 & 2.2 & 1.6 & 1.6 \\
$Q_{b}\left(\times 10^{-5} \mathrm{~m}^{2} \mathrm{~s}^{-1}\right)$ & 7.9 & 8.9 & 5.3 & 5.3 \\
$Q_{s}\left(\times 10^{-4} \mathrm{~m}^{2} \mathrm{~s}^{-1}\right)$ & 1.8 & 3.6 & 4.3 & 5.0 \\
$T_{m s}(\mathrm{yr})$ & & & & \\
Model results for most preferred mode & 4.1 & 5.9 & 5.7 & 5.7 \\
spacing $\left(\mathrm{km}^{2}\right)$ & 125 & 145 & 235 & 270 \\
e-folding time $(\mathrm{yr})$ & -2.1 & -2.6 & -3.0 & +2.9 \\
migration speed $\left(\mathrm{m} \mathrm{yr}{ }^{-1}\right)$ & & & &
\end{tabular}

TABLE 1. Input parameters and model results for the inner shelves of Long Island, Maryland, Florida and Argentina. The first part of the table shows the location and geometry of these shelves, the second the scales of the water motion and sediment fluxes and the third the model results in terms of the characteristics of the most preferred bed form.

Since the basic current $V<0$ in all these experiments, the different cases correspond to no downwelling, downwelling and upwelling conditions, respectively. The results, shown in figure 10, indicate that Earth's rotation hardly affects the topographic waves. In this regime the Coriolis force produces just an inshore shift of the ridges for upwelling conditions and an offshore shift for downwelling conditions along with a slight inhibition of the instability in the latter case.

Finally the sensitivity of the model results to the friction parameter has been investigated by varying the bottom friction coefficient $r$, but keeping the ratio $s / r$ constant and all other model parameters at their default value. Physically this means that the form drag on the bottom is increased, without changing the skin friction which forces the sediment transport. At the same time the wind stress and longshore pressure gradient are adjusted to maintain the same velocity scale $U$. It then follows that changing the form drag does not have a substantial effect on the spacing, migration and timescale of the most preferred mode.

To summarize, the model indicates that the necessary conditions for the formation of shoreface-connected sand ridges are an inner shelf with a sufficiently large transverse slope and availability of medium-fine sand. Furthermore, the common occurrence of storms with large stirring of sediment by waves is required.

\subsection{Application to other micro-tidal inner shelves}

To investigate the versatility of the model it has been applied to other micro-tidal inner shelves as well, including those located near Maryland and Florida, which are both along the east coast of the United States, and the inner shelf of Argentina (Punta Medanos). Detailed information about the shelf geometry, the water motion and the properties of these shoreface-connected ridges is given in Duane et al. (1972), Swift et al. (1981), Parker et al. (1982), see also Trowbridge (1995) and references therein.

The relevant information has been summarized in table 1, where for convenience 
values for the default shelf (Long Island) are also given. Parameters which are kept at their default value, as discussed in $\$ \S 2$ and 4.1, are the porosity $p$, the ratio $\delta$ of the suspended layer thickness and the water depth, the bed-load coefficient $v_{b}$, the alongshore wind stress $\tau_{s y}$, the grain size, exponent $m$ in the wave stirring coefficient and storm fraction $\mu$. Furthermore, the longshore pressure gradients were neglected; in the previous section it has been shown that the results are only weakly dependent on the current profile.

The main difference between the Maryland shelf and the Long Island shelf is that it is located further to the south and it is shallower and wider. Consequently the wave-orbital velocity at the transition to the shoreface is larger, resulting in a stronger friction and thereby a weaker current. The Florida shelf has a similar geometry to the Maryland shelf, but wave effects are weaker here and it is located further southward. Finally the Argentina shelf has been selected because it is located on the southern hemisphere.

The numerical model MORFO25 has been run with new values for the dimensionless parameters $\hat{f}, \beta, r, \gamma, \delta_{b}, \hat{\lambda}_{b}$ and $\hat{\lambda}_{s}$, which follow from the input parameters given in table 1 . The final model results for the spacing, e-folding timescale and migration speed of the most preferred mode are also presented in table 1 and are in good agreement with the field data.

\section{Physical interpretation}

In this section the physical mechanism responsible for the growth and observed characteristics of shoreface-connected sand ridges will be discussed. The basic concept has already been explained by Trowbridge (1995) for the case of an irrotational flow model, bed-load sediment transport without slope correction term and spatially uniform stirring by waves. He demonstrates that the necessary conditions for the growth are the presence of a transversely sloping reference bottom and that the current should have an offshore deflection over the bars. The latter occurs if the ridges have an upcurrent orientation (seaward ends of the crest shifted upstream with respect to their shoreface attachment). This is a consequence of mass conservation, which causes the cross-bank flow component to increase over the ridge. The movement of a column into deeper water will cause a mass deficit which must be compensated by a convergence of the flow. As in this situation the bed-load sediment flux, $\boldsymbol{q}_{b}$, is proportional to the velocity of the current, there will be convergence of sediment above the crests and thus the ridges will grow, see figure 11 . The convergence of the bed-load sediment flux is more effective on the downstream side of the ridge because the longshore movement of the control volume causes an additional mass deficit in this area. This causes the downstream migration of the bed forms. Thus shoreface-connected ridges are trapped at the inner shelf, because in this area the slope of the bottom is much larger than at the outer shelf.

An important new element of the present model, with respect to the one of Trowbridge (1995), is the suspended-load sediment transport. Since the main balance in the dynamics of suspended sediment concentration is between erosion and deposition (equation (3.8) if $\gamma \ll 1$ ) and the diffusive terms are small, the suspended-load sediment flux is $\boldsymbol{q}_{s} \approx K D \boldsymbol{v}$, where $K=u_{w}^{3}$ is a wave stirring coefficient. Making use of mass conservation $\nabla \cdot \boldsymbol{q}_{s}$ becomes $D \boldsymbol{v} \cdot \nabla K$. For spatially uniform wave stirring $\nabla K=0$ and therefore there will be neither growth nor migration of bed forms. If spatially non-uniform wave stirring is taken into account upcurrent rotated ridges will grow: due to the decreasing wave stirring activity with increasing water depths $(\partial K / \partial x<0)$ 


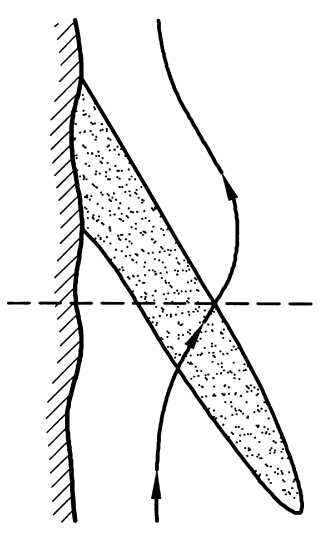

Offshore deflection

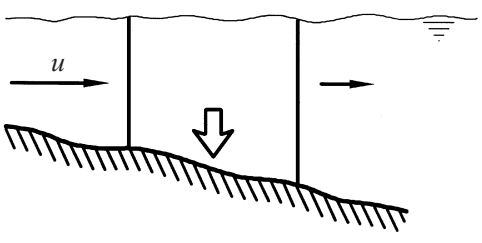

Accretion

FiguRE 11. Schematic view of the transverse bottom slope mechanism. An upcurrent oriented ridge produces offshore deflection of the flow. Then, flow into deeper water must converge so that sediment convergence occurs over the ridge.

the suspended sediment flux will converge over the bars where an offshore deflection is produced $(u>0)$. Both the bed-load flux and the suspended-load flux will act in a similar way, but spatially non-uniform wave stirring causes enhanced growth of the ridges which is crucial to predict realistic e-folding timescales. On the other hand the migration speeds are only marginally affected (a small reduction, see figure 6) by depth-dependent stirring. This stems from the fact that the phase shift between the cross-shore velocity component and the bottom perturbations is very small.

Linearizing the combination of the equations for the continuity (3.7), the concentration (3.8) and the bottom evolution (3.9) (in the limit of $F, \epsilon$ and $\gamma \rightarrow 0$ ) results in

$$
\frac{\partial h}{\partial t}+\delta_{b} \frac{V}{H^{1+m}} \frac{\partial h}{\partial y}-\nabla \cdot\left(\lambda_{e f f} \nabla h\right)=\left[\frac{3}{2} \frac{m}{H^{3 m / 2}}+\delta_{b} \frac{(m+1)}{H^{(1+m)}}\right] \frac{\mathrm{d} H}{\mathrm{~d} x} u,
$$

where $\lambda_{\text {eff }}=\hat{\lambda}_{s} H^{-5 m / 2}+\delta_{b} \hat{\lambda}_{b} H^{-3 m / 2}$. On the right-hand side are the sources of instabilities described above. The second and third terms on the left-hand side describe the migration and the diffusion of the bed forms, respectively. We remark that for $m=\lambda_{\text {eff }}=\hat{f}=r=0$ our model becomes equivalent to the one studied by Trowbridge (1995).

The behaviour of the perturbation in the sediment flux in figure 5 can be understood by analysing the suspended-load flux which yields the dominant contribution. This flux has components $u_{w}^{3} H u$ and $u_{w}^{3}(H v-V h)$ in the offshore and longshore direction, respectively. The offshore component is in phase with the offshore velocity component. The longshore component of the flux consists of two opposing contributions: for example above a crest they are directed in both the downstream and upstream directions. From the continuity equation it follows that $|v| \leqslant(h / H)|V|$, where the equal sign holds in case of transverse bars, with the consequence that the alongshore component is negative above the crest. The result is that over the bars sediment flux is deflected offshore and decreases alongshore; the opposite occurs in the trough region.

Finally we remark that in the present model the flow is rotational because of Coriolis and bottom friction forces. The latter modify the morphodynamic instability mechanism. For $V / \hat{f}<0$ (downwelling conditions), which applies to most field situations, the Coriolis force has an onshore directed component and hence will 
reduce the offshore deflection of the current over the ridges. This argument shows why in $\S 4.2$ it was found that growth rates decrease with increasing values of the Coriolis parameter, although the effect is quite weak.

\section{Discussion}

The main indication of the present study is that shoreface-connected sand ridges will only form on inner shelves with a sufficiently large transverse slope and with the bottom consisting of medium to fine sand. Also, severe storms should frequently occur, resulting in both an alongshore current and strong wave orbital motion near the bed. As a consequence sediment will be stirred by waves and transported (as suspended load) by the mean current. This picture seems to be confirmed by the field observations of Green et al. (1995).

However the model is a gross simplification of reality. As can be seen from figures 171-173 in Duane et al. (1972) or figure 1 in Parker et al. (1982) the observed patterns of shoreface-connected ridges are rather complex and the elongated shape and upcurrent orientation are only indicative of the mean characteristics. Many ridges have secondary shoals (see e.g. figure 4 in Swift et al. 1978) which suggests that other mechanisms may play a role.

First, the vertical structure of the currents is neglected. As shown by e.g. Niedoroda et al. (1984) and Niedoroda \& Swift (1991) the three-dimensional flow structure during a storm leads to an offshore directed sediment transport during storms. This will modify the two-dimensional mechanisms analysed in the present study. Also, a three-dimensional model will probably generate new bed-flow couplings. The analysis of a three-dimensional flow over an uneven bed, which is a complicated problem, is considered to be an important topic for future research. Secondly, nonlinear terms in the equations for the perturbations have been ignored in the present study. Thus, a challenging issue is to perform a nonlinear finite-amplitude analysis of the ridge behaviour, which would lead to a prediction of the amplitude of the ridges. This kind of nonlinear modelling is at present under investigation and preliminary results for uniform wave stirring and only bed-load sediment transport have been discussed in Calvete et al. (1999). Thirdly, the transport of sediment during fair weather conditions is ignored in the present model. If present, then the relation between the sediment fluxes and the current is highly nonlinear, as can be seen from the parametrizations discussed in Bailard (1981), Fredsoe \& Deigaard (1993) and Van Rijn (1993). If this regime is studied for a steady reference flow, see Falqués et al. (1998a), other types of bottom modes are obtained.

The discussion above suggests that it is preferable to specify a storm climatology and run the model partly in the severe weather mode and partly in the fair weather mode. This is a difficult problem because it requires the use of different velocity profiles and different velocity amplitudes for each situation. Clearly such an approach cannot be avoided in the case of strong tidal oscillations, as observed on the mesotidal Dutch and German inner shelf: here sediment will also be transported during fair weather. Examination of the large-scale bed forms along the central Dutch coast, see figure 1 of Van de Meene et al. (1996), does not immediately reveal their identity: they could be shoreface-connected ridges or, alternatively, tidal sand banks distorted by the proximity of the coast. The present study indicates that these two types of bed forms have an entirely different origin. Indeed, tidal sand banks are associated with 'faster than linear' dependence of the sediment transport on the current and also Earth's rotation plays an important role (Huthnance 1982; Hulscher et al. 1993). On 
the other hand, the correct orientation of the observed ridges can only be predicted with a model accounting for the instability mechanism related to the transverse slope, which is only effective during storms. This type of modelling is however beyond the scope of the present study.

The parameter $\delta$ (ratio of the suspended sediment layer thickness and the water depth) has been taken constant over the inner shelf. The motivation of this choice was that the turbulent mixing coefficient for sediment particles is proportional to the water depth. In general, this mixing coefficient will also be proportional to the wave orbital velocity. In such a case $\delta$ will decrease in the offshore direction with the consequence of an enhancement of the spatially non-uniform wave stirring. The final effect will be a small increase of growth rates. Due to the lack of observations of the thickness of the suspended sediment layer during storms a constant $\delta$ has been chosen.

The explicit formulation of the wave stirring used in this study, see equation (2.5), is based on a simple wave shoaling model. It assumes that the waves are linear, nearly symmetrical and that their direction of propagation almost coincides with that of the current. It is important to mention that the effects of the rhythmic bed forms on the wave stirring has not been taken into account. If this were done in a straightforward manner, by replacing the undisturbed water depth $H$ in $(2.5)$ by $(H-h)$, it would result in an increased stirring above the ridges and smaller stirring in the troughs. Such a generalization is in fact not allowed, because the parametrization is strictly only valid for parallel depth contours. Clearly, there are other effects which will cause a reduction of wave stirring above the crests. One of them is wave refraction, because it causes the distance between rays to become larger towards shallower depths. Another relevant process is the partial breaking of the largest waves above the ridges, thereby resulting in a decreased wave amplitude. To account properly for the effect of bed forms on the wave stirring, a sophisticated wave transformation model based on the eikonal equation would be required, but this is beyond the scope of the present study.

\section{Conclusions}

The main objective of the present study was to obtain a better understanding of the presence and characteristics of shoreface-connected sand ridges, as observed on the inner shelf of some coastal seas. It was argued that such large-scale bed forms form due to a positive feedback between the water motion and the erodible bottom. The hypothesis has been studied in the framework of a depth-integrated shallow water model, supplemented with a sediment transport parametrization and a bottom evolution equation. It extends an earlier model developed by Trowbridge (1995) in that Coriolis and bottom frictional forces are included. Moreover, the sediment transport is due to both suspended-load and bed-load processes and it explicitly accounts for the effects of depth-dependent wave stirring as well as for the tendency of the sediment to move downslope.

The background of the model is a basic state which is uniform in the direction parallel to the coast. It describes a steady mean longshore flow, driven by wind and a pressure gradient, over a reference topography. The stability properties of this morphodynamic equilibrium with respect to small bottom pertubations, which are rhythmic in the longshore direction, have been investigated. A systematic analysis of the model has revealed that inherent morphologic instabilities do indeed develop and that their properties depend on the model parameters. Necessary conditions for shoreface-connected ridges to develop are a shelf with a large transverse slope and 
the availability of medium to fine sand. Moreover, the frequent occurrence of storms is required with associated large wave orbital motions near the bottom and a mean alongshore flow.

In all cases investigated scale selection occurs, i.e. the growth rate curves attain a maximum for a specific alongshore wavenumber. The corresponding dominant bed forms appear to be trapped at the inner shelf and are rotated upcurrent, i.e. the seaward ends of the crests are shifted upstream with respect to where they are attached to the shoreface. Both the predicted wavelength and spatial structure are in good agreement with observations of shoreface-connected sand ridges on many different storm-dominated shelves. Physically, their formation results from an instability mechanism which stems from the transverse slope of the reference bottom; the latter also causes an offshore current deflection over the bars. It has been demonstrated that these characteristics can be understood from mass conservation of both the water and the sediment.

The growth of the bed forms appears to be mainly determined by the suspendedload flux, because it is much larger than the bed-load contribution, see Green et al. (1995). The latter on the other hand controls the downstream celerity of the ridges. This remarkable property is a consequence of the fact that the deposition of suspended sediment depends on the depth-averaged sediment concentration (rather than on its depth-integrated value). This causes spatial variations in the suspended-load flux to be almost in phase with the bottom perturbations and to be only effective for spatially non-uniform wave stirring.

If the timescales related to the growth and migration of the bed forms are compared with field observations of shoreface-connected sand ridges on an inner shelf, it turns out that good results are only found when both suspended-load sediment fluxes and depth-dependent wave stirring are taken into account. Their incorporation also removes the sensitive dependence of the model results on the detailed properties of the reference current profile. Hence the model analysed in this paper is an important generalization of the models already discussed by Trowbridge (1995) and Falqués et al. $(1998 a, b)$.

Notwithstanding all the limitations discussed in the previous section it therefore seems that the analysis of the present model has contributed to the fundamental processes underlying the formation and maintenance of the ridges.

This paper is based on work on the PACE-project, in the framework of the EUsponsored Marine Science and Technology Programme (MAST3), under contract no. MAS3-CT95-0002. Part of the research has been done during a stay of Daniel Calvete and Albert Falqués at Utrecht, (IMAU). The visit of Albert Falqués was partially funded by RIKZ (National Institute of Coastal and Marine Management, The Netherlands). Part of this work was also supported by CLS (Cornelis Lely Foundation). This research is an extension of earlier work by Amadeu Montoto. His advice and support are gratefully acknowledged.

\section{REFERENCES}

AnTIA, E. E. 1996 Shoreface-connected ridges in German and US Mid-Atlantic bights: similarities and contrasts. J. Coastal Res. 12, 141-146.

BAILARD, J. A. 1981 An energetics total load sediment transport model for a plane sloping beach. J. Geophys. Res. 86 (C11), 10938-10954.

Blondeaux, P. 1990 Sand ripples under sea waves. Part 1. Ripple formation. J. Fluid Mech. 218, $1-17$. 
Calvete, D., Falqués, A., De Swart, H. E. \& Dodd, N. 1999 Nonlinear modelling of shorefaceconnected sand ridges. In Coastal Sediments '99, vol. 2 (ed. N. C. Kraus \& W. G. McDougal), pp. 1123-1138. ASCE, Reston (VI).

Chase, R. R. P. 1979 The coastal longshore pressure gradient: temporal variations and driving mechanisms. J. Geophys. Res. 84, 4898-4904.

Christensen, E., Deigaard, R. \& Fredsoe, J. 1994 Sea bed stability on a long straight coast. In Coastal Engineering 1994 (ed. B. L. Edge), vol. 2, pp. 1865-1879. ASCE.

Duane, D. B., Field, M. E., Miesberger, E. P., Swift, D. J. P. \& Williams, S. 1972 Linear shoals on the Atlantic continental shelf, Florida to Long Island. In Shelf Sediment Transport: Process and Patterns (ed. D. J. P. Swift, D. B. Duane \& O. H. Pilkey). Dowden, Huthcingson and Ross, Stroudburg (USA).

Falqués, A., Calvete, D., De Swart, H. E. \& Dodd, N. 1998a Morphodynamics of shorefaceconnected ridges. In Coastal Engineering 1998 (ed. B. L. Edge), pp. 2851-2864. ASCE, Reston (VI).

Falqués, A., Calvete, D. \& Montoto, A. 1998 b Bed-flow instabilities of coastal currents. In Physics of Estuaries and Coastal Seas (ed. J. Dronkers \& M. B. A. M. Scheffers), pp. 417-424. Balkema, Rotterdam.

Falqués, A., Montoto, A. \& Iranzo, V. 1996 a Bed-flow instability of the longshore current. Cont. Shelf Res. 16 (15), 1927-1964.

Falqués, A., Montoto, A. \& Iranzo, V. 1996 Coastal morphodynamic instabilities. In Proc. 25th ASCE Intl Conf. on Coastal Engineering, vol. 3 (ed. B. L. Edge), pp. 3560-3573. Reston, VA.

Fredsoe, J. \& DeigaArd, R. 1993 Mechanics of Coastal Sediment Transport. World Scientific, Singapore.

Green, M. O., Vincent, C. E., McCave, I. N., Dickson, R. R., Rees, J. M. \& Pearson, N. 1995 Storm sediment transport: observations from the British North Sea shelf. Cont. Shelf Res. 15 (8), 889-912.

HINO, M. 1974 Theory on formation of rip-current and cuspidal coast. In Proc. 14th ASCE Intl Conf. Coastal Engineering, pp. 901-919.

Hulscher, S. J. M. H. 1996 Tidal-induced large-scale regular bed form patterns in a threedimensional shallow water model. J. Geophys. Res. 101 (C9), 20727-20744.

Hulscher, S. J. M. H., De Swart, H. E. \& De VRIend, H. J. 1993 The generation of offshore tidal sand banks and sand waves. Cont. Shelf Res. 13 (11), 1183-1204.

Huthnance, J. M. 1982 On one mechanism forming linear sand banks. Est. Coastal Shelf Sci. 14 79-99.

Jenter, H. L. \& Madsen, O. S. 1989 Bottom stress in wind-driven depth-averaged coastal flows. J. Phys. Oceanogr. 19, 962-974.

Lentz, S., Guza, R. T., Elgar, S., Feddersen, F. \& Herbers, T. H. C. 1999 Momentum balances on the North Carolina shelf. J. Geophys. Res. 104 (C8), 18205-18226.

Lentz, S. J. \& Winant, C. D. 1986 Subinertial currents on the southern California shelf. J. Phys. Oceanogr. 16, 1737-1750.

Niedoroda, A. W. \& Swift, D. J. P. 1981 Maintenance of the shoreface by wave orbital currents and mean flow: observations from the Long Island coast. Geophys. Res. Lett. 8, 337-340.

Niedoroda, A. W. \& Swift, D. J. P. 1991 Shoreface processes. In Handbook of Coastal and Ocean Engineering (ed. J. B. Herbich), pp. 736-769. Gulf Publ. Co., Houston.

Niedoroda, A. W., Swift, D. J. P. \& Hopkins, T. S. 1984 Shoreface morphodynamics on wavedominated coasts. Mar. Geol. 60, 331-354.

Parker, G., Lanfredi, N. W. \& Swift, D. J. P. 1982 Seafloor response to flow in a Southern Hemisphere sand-ridge field: Argentina inner shelf. Sedimentary Geol. 33, 195-216.

Schielen, R., Doelman, A. \& De Swart, H. E. 1993 On the nonlinear dynamics of free bars in straight channels. J. Fluid Mech. 252, 325-356.

Scott, J. T. \& Csanady, G. T. 1976 Nearshore currents off Long Island. J. Geophys. Res. 81, 5401-5409.

Swift, D. J. P., Niedoroda, A. W., Vincent, C. E. \& Hopkins, T. S. 1985 Barrier island evolution, Middle Atlantic Shelf, U.S.A., part 1: shoreface dynamics. Mar. Geol. 63, 331-361.

Swift, D. J. P., Parker, G., Lanfredi, N. W., Perillo, G. \& Figge, K. 1978 Shoreface-connected sand ridges on American and European Shelves: A Comparison. Est. Coast. Mar. Sci. 7, $257-273$. 
Swift, D. J. P., Young, R. A., Clarke, T. L., Vincent, C. E., Niedoroda, A. \& Lesht, B. 1981 Sediment transport in the Middle Atlantic Bight of North America: synopsis of recent observations. Spec. Publs. Intl Ass. Sediment. 5, 361-383.

Trowbridge, J. H. 1995 A mechanism for the formation and maintenance of shore-oblique sand ridges on storm-dominated shelves. J. Geophys. Res. 100 (C8), 16071-16086.

Van de Meene, J. W. H., Boersma, J. R. \& Terwindt, J. H. J. 1996 Sedimentary structures of combined flow deposits from the shoreface-connected ridges along the central Dutch coast. Mar. Geol. 131, 151-175.

VAN Risn, L. C. 1993 Principles of Sediment Transport in Rivers, Estuaries and Coastal Seas. Aqua, Amsterdam.

Williams, J. J., Rose, C. P., Thorne, P. D., O’Connor, B. A., Humphery, J. D., Hardcastle, P. J., Moores, S. P., Cooke, J. A. \& Wilson, D. J. 1999 Field observations and predictions of bed shear stresses and vertical suspended sediment concentration profiles in wave-current conditions. Cont. Shelf Res. 19, 507-536.

Zimmerman, J. T. F. 1981 Dynamics, diffusion and geomorphological significance of tidal residual eddies. Nature 290, 549-555. 